\title{
Peutz-Jeghers syndrome without polyposis
}

\author{
Anthony G. CATto-Smith, MB, BS, FRACP, MRCP, MARK K. PATRICK, MB, BS, FRACP, \\ D. GRANT GALL, MD, FRCPC
}

ABSTRACT: Peutz-Jeghers syndrome is generally considered a condition in which familial gastrointestinal polyposis is associated with a characteristic pigmentation of the skin and mucous membranes. Two me mbers of a family in which the characteristic pigmentation was present in the absence of gastrointestinal polyposis are reported. These patients highlight the importance of defining the intestinal lesion associated with this syndrome. Can J Gastroenterol 1988;2(3):117-118.

Key Words: Peutz-Jeghers syndrome, Variable expressivity

P EUTZ-JEGHERS SYNDROME. AS DE. scribed originally, linked the association of familial gastrointestinal polyposis with a characteristic pigmentation of the skin and mucous membranes (1). No literature is available to provide an accurate estimate of its prevalence, but some authors have suggested that it may be as common as familial polyposis coli 12), with an incidence of $1: 8300$ births (3). The common presentation of Peutzleghers syndrome is that of repeated episodes of abdominal pain due to recurrent small intestinal intussusception during the first decades of life. These episodes usually resolve spontaneously but occasionally necessitate repeated laparotomies. Hematochezia may also be an ini- tial manifestation. There is an increased risk of intestinal malignancy, approximately 2 to $3 \%$ (4-6). These complications are associated with the intestinal polyposis. However, the syndrome may demonstrate variable expressivity.

A boy of five years, 10 months was referred to the Pediatric Gastroenterology Clinic in Calgary because of pigmentation on his lips and buccal mucosa. Except for mild speech delay he had always been a well child. On systemic enquiry he had not had problems with abdominal pain, vomiting, rectal bleeding or diarrhea. Growth pattern was normal.

\section{CASE PRESENTATION}

Division of Pediatric Gastroenterology and Nutrition. Department of Pediatrics, University of Calgary, Calgary. Alberta

Correspondence and reprints: Dr D. Grant Gall, Department of Pediatrics, Health Science Catre, 3330 Hospital Drive NW. Calgary, Alberta T2N 4N1. Telephone (403) 220-7370

Received for publication May 16, 1988. Accepted July 27, 1988

Family history revealed that the mother, aged 28 years, had similar pigmentation which was first noted in early life. Subsequently, a diagnosis of PeutzJeghers syndrome was made on the basis of the pigmentation only and the possible complications were outlined to the mother. However, she remained totally asymptomatic and specifically denied any gastrointestinal symptomatology. The father was well; the patient was an only child. There was no family history of polyposis or other individuals with oral pigmentation.

Investigations of the patient demonstrated normal complete blood count and urinalysis. Barium contrast studies of the upper gastrointestinal tract and small intestine were interpreted as normal with no evidence of polyps (Figure 1). In light of this result, radiographic studies were carried out in the mother which also failed to reveal any evidence of polyposis.

\section{DISCUSSION}

The characteristic pigmentation of Peutz-Jeghers syndrome has been described as its sine qua non (7). The pigmentation is often present at birth, but may not appear until later. Utsunomiya (8) in a nationwide Japanese survey ascertained 222 patients with Peutz-Jeghers syndrome and found only five without 


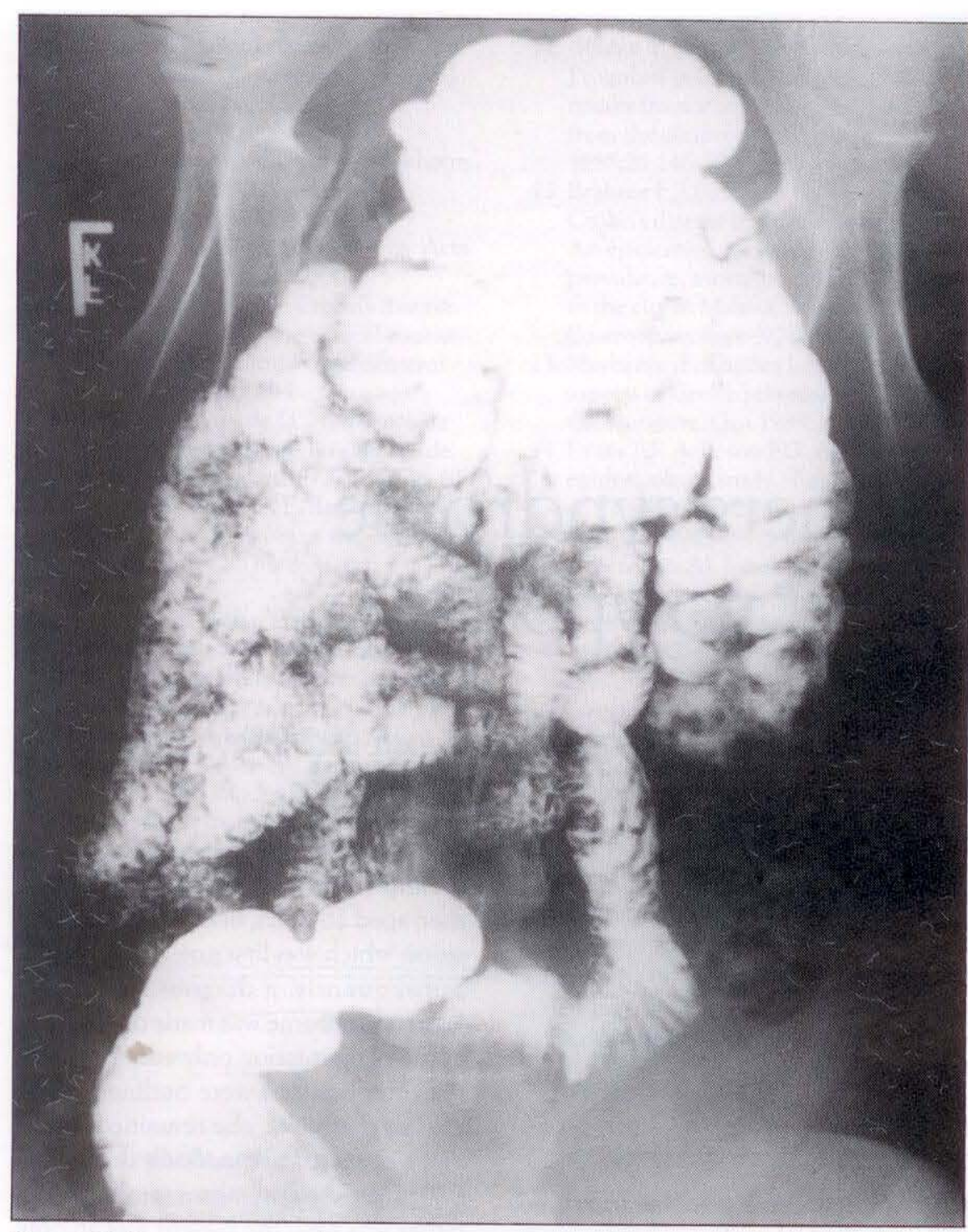

Figure 1) Barium contrast study of the upper gastrointestinal tract and small intestine showing no evidence of polyposis labial pigmentation. However, in these patients pigmentatory changes were noted on buccal mucosa or digits. The patients were all over 45 years old and it has been suggested that lip pigmentation may fade with increasing age (5).

Discordance between pigmentation and polyposis has been previously described (9-11). Variable expressivity is a frequent feature of autosomal dominantly inherited conditions (12). Where malignant change occurs, it is usually a duodenal adenocarcinoma, although other parts of the bowel may be involved $(5,13)$, and intestinal malignancies are thought to arise from polyps.

With the recognition of a malignant potential for Peutz-Jeghers syndrome,

\section{Le syndrome de Peutz-Jeghers sans polypose}

RESUME: En général, le syndrome de Peutz-Jeghers est vu comme une condition dans laquelle la polypose gastrointestinale familiale est associée avec une pigmentation caractéristique de la peau et des membranes muqueuses. Nous rapportons le cas de deux membres d'une même famille chez qui cette pigmentation existe en l'absence de polypose gastrointestinale. Ces patients attirent notre attention sur l'importance d'une définition des lésions intestinales associées avec ce syndrome. some authors have suggested annual screening for gastrointestinal polyps and local resection of any polyps larger than $2 \mathrm{~cm}$ in diameter, and all gastric or dudodenal polyps (8). The risk of intestinal malignancy and the other intestinal complications are presumably absent in those patients with Peutz-Jeghers syndrome who present without polyposis. The patients described highlight the importance of defining the intestinal lesion associated with the syndrome.

\section{REFERENCES}

1. Jeghers $\mathrm{H}$, McKusick VA, Katz $\mathrm{KH}$. Generalized intestinal polyposis and melanin spots of the oral mucosa, lips and digits. N Engl J Med 1949;241:1031-6.

2. Dormandy TL. Gastrointestinal polyposis with mucocutaneous pigmentation (Peutz-Jeghers syndrome). N Engl J Med 1957;256:1093-103.

3. Forbes D, Rubin S, Trevenen C, Gall DG, Scott B. Familial polyposis coli in childhood. Clin Invest Med 1987; 10:5-9.

4. Bulow S. Colorectal polyposis syndromes. Scand J Gastroenterol 1984;19:289-93.

5. Erbe RW. Inherited gastrointestinal polyposis syndromes. N Engl J Med 1976;294:1101-4.

6. McKusick VA. Mendelian inheritance in man, 7th edn. Baltimore: Johns Hopkins University Press, 1986:614-5.

7. Wenzl JE, Bartholomew LG, Hallenbeck GA, Stickler GB. Gastrointestinal polyposis with mucocutaneous pigmentation in children (Peutz-Jeghers syndrome). Pediatrics 1961;28:655-61.

8. Utsunomiya J, Gocho H, Miyanaga T, et al. Peutz-Jeghers syndrome: Its natural course and management. Johns Hopkins Med J 1975;136:71-82.

9. Farmer RG, Hawk WA, Turnbull RB. The spectrum of the Peutz-Jeghers syndrome. Am J Dig Dis 1963:8:953-61.

10. Kieselstein M, Herman G, Wahrman J, et al. Mucocutaneous pigmentation and intestinal polyposis (Peutz-Jeghers syndrome) in a family of Iraqi Jews with polycystic kidney disease. Isr J Med Sci 1969;5:81-90.

11. Brigg JK, Taylor TV. Torrance HB. Unusual manifestations of the Peutz-Jeghers syndrome. Br Med J 1976;2:853.

12. Goodenough U. Genetics, 3rd edn. Philadelphia: Saunders College Publishing, 1984:602-3.

13. Bussey HJR, Veale AMO, Morson BC Genetics of gastrointestinal polyposis. Gastroenterology 1978;74:1325-30. 


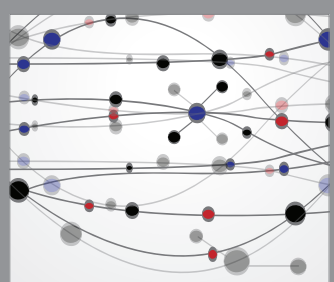

The Scientific World Journal
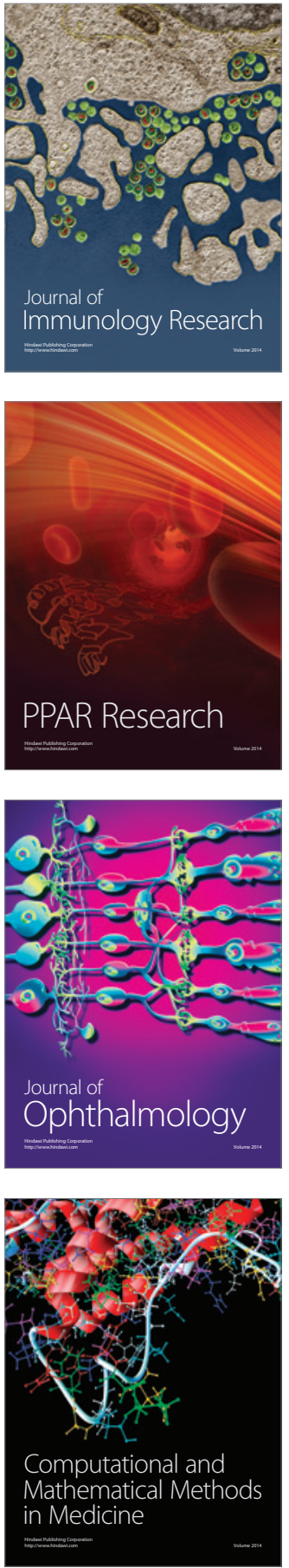

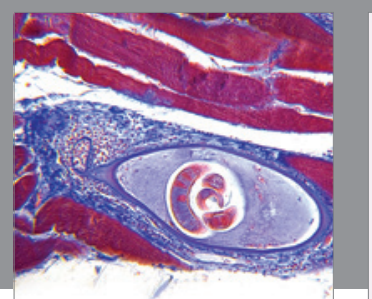

Gastroenterology Research and Practice

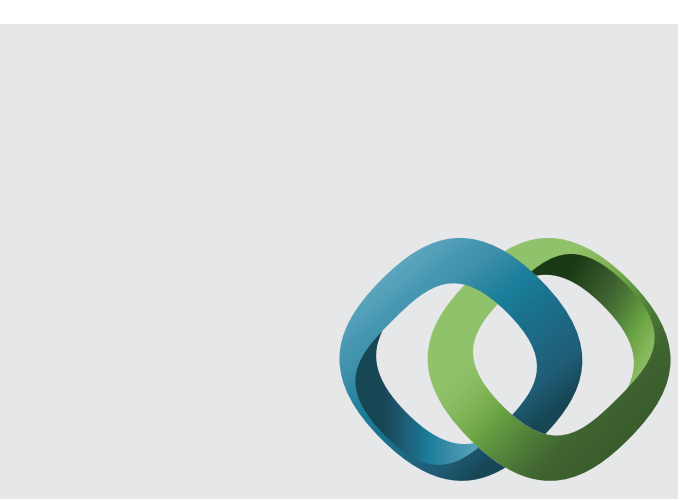

\section{Hindawi}

Submit your manuscripts at

http://www.hindawi.com
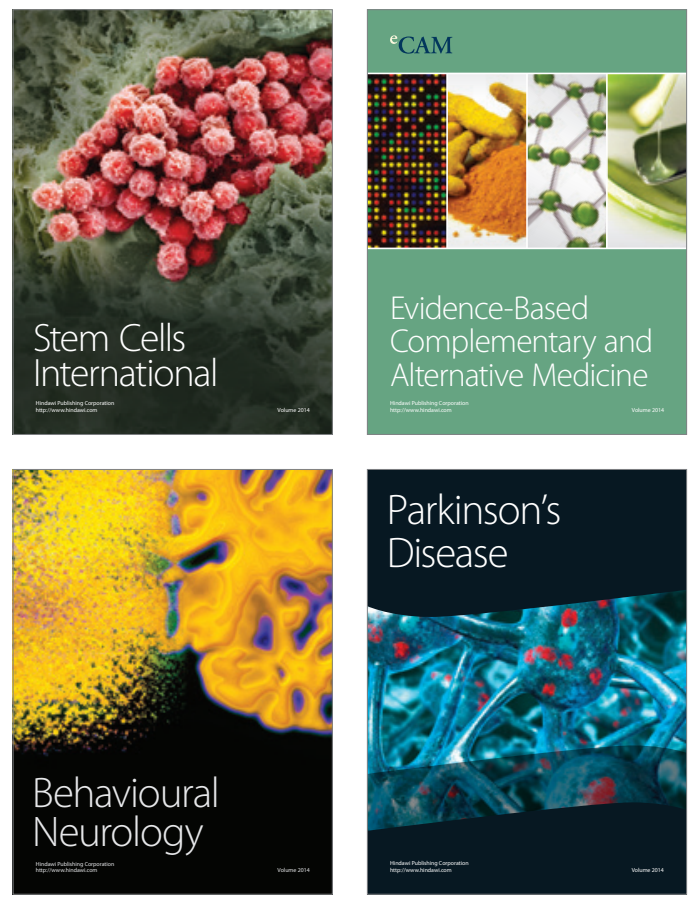
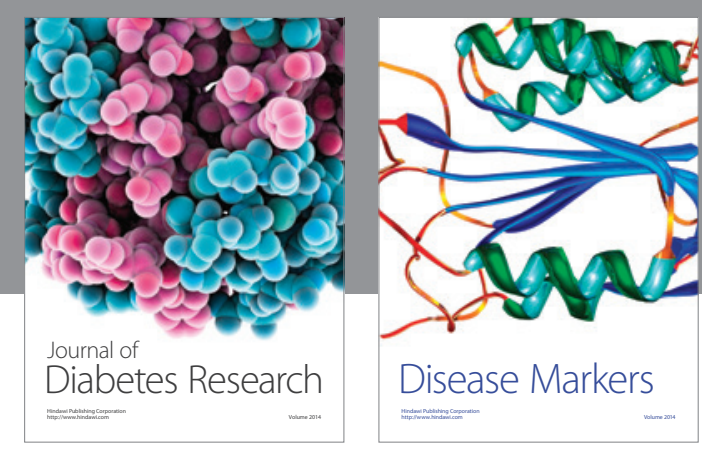

Disease Markers
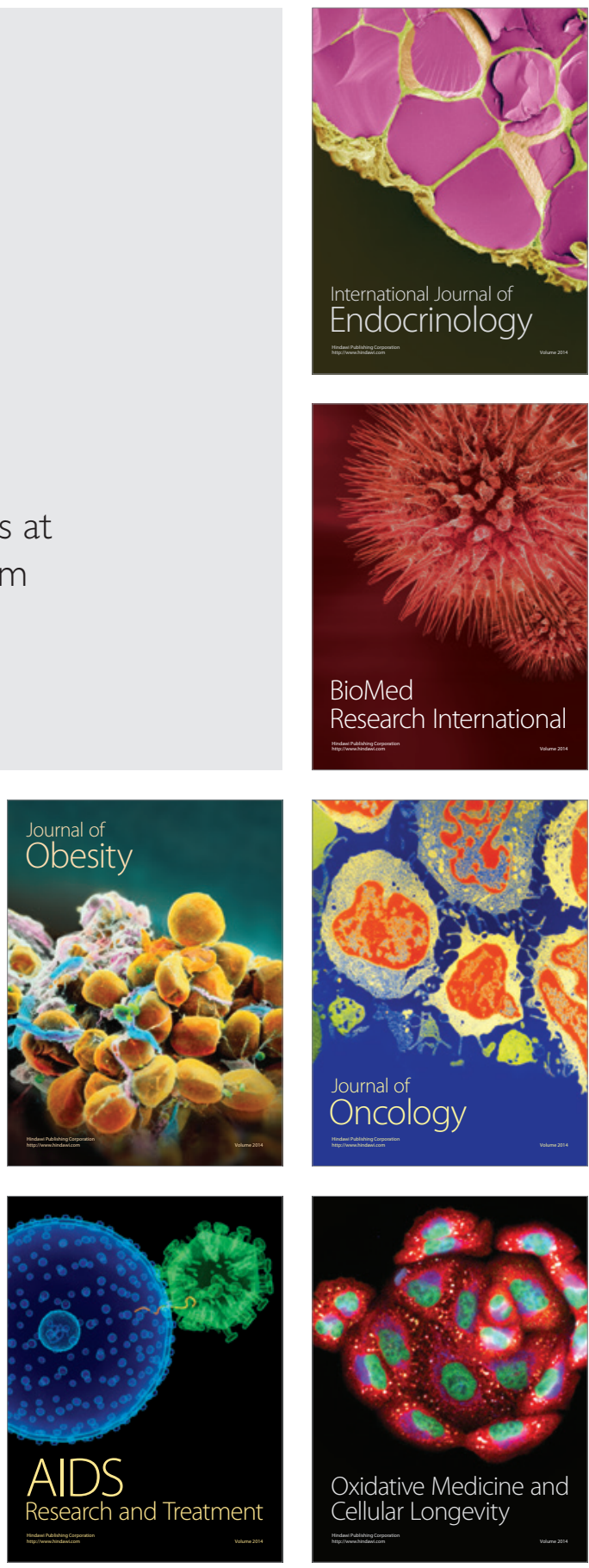